\title{
$\mathbb{A}$ Economics Bulletin
}

Volume 36, Issue 2

\section{Time-Varying Employment Risks, Consumption Composition, and Fiscal Policy}

\author{
Kazufumi Yamana \\ Graduate School of Economics, Hitotsubashi University
}

Makoto Nirei

Institute of Innovation Research, Hitotsubashi University

\author{
Sanjib Sarker \\ Utah State University
}

\begin{abstract}
This study examines the response of aggregate consumption to active labor market policies that reduce unemployment. We develop a dynamic general equilibrium model with heterogeneous agents and uninsurable unemployment as well as policy regime shocks to quantify the consumption effects of policy. By implementing numerical experiments using the model, we demonstrate a positive effect on aggregate consumption even when the policy serves as a pure transfer from the employed to the unemployed. The positive effect on consumption results from the reduced precautionary savings of the households who indirectly benefit from the policy by a decreased unemployment hazard in future.
\end{abstract}

Citation: Kazufumi Yamana and Makoto Nirei and Sanjib Sarker, (2016) "Time-Varying Employment Risks, Consumption Composition, and Fiscal Policy", Economics Bulletin, Volume 36, Issue 2, pages 802-812

Contact: Kazufumi Yamana - kz.yamana@gmail.com Makoto Nirei - mnirei@gmail.com, Sanjib Sarker - sanjsar@gmail.com.

Submitted: November 05, 2015. Published: April 29, 2016. 


\section{Introduction}

There is a growing interest in labor market policies as effective macroeconomic policy instruments to combat unemployment (Nie and Struby (2011)) that has been used conservatively to help the unemployed. Two major questions presented in this literature are as follows: (i) What is the effect of the policy on the labor market performance of program participants? and (ii) What is the general equilibrium consequence of such policy? While there have been extensive microeconometric evaluations and discussions that have led to a consensus on the first question, the second question is unanswered because the indirect effects of the programs on nonparticipants via general equilibrium adjustments are inconclusive. Heckman, Lalonde and Smith (1999) pointed out that the commonly used partial equilibrium approach implicitly assumes that the indirect effects are negligible and can therefore produce misleading estimates when the indirect effects are substantial.

This study investigates the indirect effects of labor market policy by focusing on the effect of reduced unemployment risk on aggregate consumption. When the unemployment rate is lowered because of the labor market program, the expected future wealth of workers increases and therefore the need for present precautionary savings decreases not only for the program participants(the treatment group), but also for the nonparticipants(the control group). We numerically analyze the precautionary savings channel for the impact of this reduced unemployment risk and quantify the indirect effect on the consumption of nonparticipants.

Our analysis is based on a general equilibrium model with uninsurable idiosyncratic unemployment risk and aggregate shock as proposed by Krusell and Smith, Jr. (1998) (henceforth referred to as KS). The magnitude of the unemployment risk changes in tandem with the level of unemployment because a high unemployment rate is associated with a longer average spell of unemployment. Thus, when the rate of unemployment is reduced by the labor market policy, the unemployed have a higher chance of finding jobs. This perceived lower risk of future unemployment leads to less demand for precautionary savings and more demand for current consumption even for the present workers and the unemployed nonparticipants who do not benefit directly from the program.

The link between the labor market policy and precautionary savings was examined by Engen and Gruber (2001), who found evidence that unemployment insurance reduces household savings. This study investigates the aggregate consequences of the precautionary savings motive when the employment risk fluctuates. In our model, aggregate fluctuations in the economy are driven by a stochastic regime switch between passive and active regimes. In our first set of experiments, we consider direct job creation by government employment as an active policy. In essence, it is a pure transfer policy from the employed to a randomly selected fraction of the unemployed. Such a transfer constitutes an important fraction of the various fiscal expenditures that relate to purchases. Empirically, Oh and Reis (2012) and Cogan and Taylor (2012) reported that approximately three-quarters of the U.S. stimulus package from 2007-Q4 to 2009-Q4 was allocated to transfers. The transfer in our model is represented by the government employment of workers. If there were a complete market for each idiosyncratic employment risk, such a transfer policy would not affect household consumption at all. We are interested in the extent to which the lack of complete markets alters this prediction. In the second set of experiments, we consider employment incentives from a regime switch in the corporate tax rate in an economy with real wage rigidity. In this case, the labor input and thus the goods output varies along with the policy shock. The difference between the first and second set of exercises lies in who hires the additional labor - the public sector or the private sector.

This paper combines two threads of the literature-the general equilibrium effect of active 
labor market policies (ALMPs) and a precautionary saving behavior. ALMPs mainly consist of job-search assistance, job-training programs, employment support, direct job creation, and employment incentives, among others. While the first three policies affect the labor supply, the latter two policies (direct job creation ${ }^{1}$ and employment incentives ${ }^{2}$ ) affect the labor demand. Our study investigates the latter set as the policy instruments. Only a few papers have investigated the general equilibrium effect of ALMPs. Calmfors (1994) discussed the several indirect effects of ALMPs which are neglected in the partial equilibrium approach. Meyer (1995) studied a deadweight effect, Davidson and Woodbury (1993) stduied a displacement effect, and Heckman, Lochner and Taber (1998) studied a substitution effect. Our study augments the literature by investigating the unemployment risk effect on consumption.

Another related topic in the literature is the precautionary saving effect on the aggregate consumption. The macroeconomic effects of precautionary savings have been analyzed by Aiyagari (1994), Carroll (2001), Huggett (1997), and Lusardi (1997), among others. Krusell and Smith, Jr. (1998) formalized a dynamic general equilibrium model with incomplete markets and aggregate and idiosyncratic shocks. Carroll (2001) argued that the KS model underestimates the precautionary savings effect. Heathcote (2005) found a quantitatively significant impact of tax changes on consumption in the KS economy. This study investigates a new consumption effects mechanism by focusing on the time-varying unemployment hazard.

The remainder of the paper is organized as follows. The next section presents the model where we modify the KS model. Section 3 shows our numerical results. Section 4 concludes the paper. The details of our computational methods, calibration, numerical results, and robustness checks are mentioned below in the Appendix.

\section{Model}

We consider a dynamic stochastic general equilibrium model with incomplete markets, uninsurable employment shocks, and aggregate shocks as in KS. We study the KS economy rather than the steady state of Aiyagari (1994) economy, because we are interested in the effect of temporary policy. The economy is populated by a continuum of households with the population normalized to one. The households maximize their utility subject to budget constraints as follows:

$$
\begin{array}{ll} 
& \max _{c_{i, t}, k_{i, t+1}} \mathrm{E}_{0} \sum_{t=0}^{\infty} \beta^{t} c_{i, t}^{1-\sigma} /(1-\sigma) \\
\text { s.t. } & c_{i, t}+k_{i, t+1}=\left(r_{t}+1-\delta\right) k_{i, t}+\imath\left(h_{i, t}\right) w_{t}-\tau\left(h_{i, t}, z_{t}\right), \quad \forall t \\
& k_{i, t+1} \geq-\phi, \quad \forall t
\end{array}
$$

where $c_{i, t}$ is consumption, $k_{i, t}$ is capital assets, $h_{i, t}$ is the employment status, $\tau\left(h_{i, t}, z_{t}\right)$ is the lump-sum tax, $r_{t}$ is the net return to capital, and $w_{t}$ is the real wage in which the consumption good is the numeraire. Capital depreciates at the rate of $\delta$, and the future utility is discounted by $\beta$. The households are subject to a borrowing constraint with a debt limit $\phi$. The households are either unemployed $\left(h_{i, t}=0\right)$ or employed $\left(h_{i, t}=1\right)$, and $h_{i, t}$ follows an exogenous process, as discussed below. The households receive wage income when employed, whereas they depend on unemployment insurance when unemployed, which is financed by taxation of the employed:

$$
\imath\left(h_{i, t}\right)= \begin{cases}1 & h_{i, t}=1 \\ 0.2 & h_{i, t}=0 .\end{cases}
$$

\footnotetext{
${ }^{1}$ Direct job creation is a policy that creates nonmarket jobs in the public sector.

${ }^{2}$ An employment incentive is a policy that subsidizes the private sector to hire new employees.
} 
The representative firm produces goods with the technology specified by a Cobb-Douglas production function with constant returns to scale $Y_{t}=K_{t}^{\alpha} H_{t}^{1-\alpha}$, where $Y_{t}$ represents the aggregate goods produced and $K_{t}$ and $H_{t}$ represent the aggregate capital and labor, respectively. The firm maximizes its profit in a competitive market, where the first-order conditions hold: $r_{t}=\alpha\left(K_{t} / H_{t}\right)^{\alpha-1}$ and $w_{t}=(1-\alpha)\left(K_{t} / H_{t}\right)^{\alpha}$.

Our model features a fiscal expansion that affects the labor market as an aggregate shock. We first consider a government employment program. The fiscal policy $z_{t}$ follows a Markov process with two states $\{0,1\}$ and a transition matrix $\left[\pi_{z z^{\prime}}\right]$. We allow $z_{t}$ to affect the transition probability of the individual employment state, $h_{i, t}$. Let $\Pi$ denote the transition matrix for the pair comprising the employment status and fiscal policy states, $\left(h_{i, t}, z_{t}\right)$. The transition probability from $(h, z)$ to $\left(h^{\prime}, z^{\prime}\right)$ is denoted by $\pi_{h h^{\prime} z z^{\prime}}$.

The labor market policy is passive in state $z_{t}=0$ and the government supplies only the unemployment insurance. The lump-sum tax is determined as $\tau(1,0)=0.2 w_{t} u_{0} /\left(1-u_{0}\right)$ and aggregate unemployment stays at a high rate, $u_{0}$. In state $z_{t}=1$, the government employs a fraction of the unemployed at the wage rate $w_{t}$ as well as supplies the unemployment insurance. The fraction of the unemployed nonparticipants amounts to $u_{1}<u_{0}$. The government employment program is financed by a lump-sum tax on the employed workers so that the government budget is balanced in each period. Thus, the tax is determined as $\tau(1,1)=0.2 w_{t} u_{1} /\left(1-u_{1}\right)+w_{t}\left(u_{0}-u_{1}\right) /\left(1-u_{1}\right)$. The unemployed do not pay tax for any $z_{t}: \tau\left(0, z_{t}\right)=0$. Note that the aggregate labor supply for firms is exogenously constant at $H_{t}=1-u_{0}$ for any $t$ regardless of $z_{t}$, whereas the total number of workers employed by firms or government is either $1-u_{0}$ or $1-u_{1}$, depending on $z_{t}$. We assume that the government is non-productive and its employment does not produce goods.

A recursive competitive equilibrium is defined as follows. The household's maximization problem is written as a dynamic programming problem with state variables $(k, h, z, \Gamma)$, where $\Gamma$ is the cross-sectional distribution of $\left(k_{i}, h_{i}\right)$ across households $i \in[0,1]$. The law of motion for $(h, z)$ is determined by the exogenous transition matrix $\Pi$. We define the transition function $T$ that maps $\Gamma$ to the next period distribution as $\Gamma^{\prime}$. The recursive competitive equilibrium is defined by the value function, $V(k, h, z, \Gamma)$; the households' policy function, $F(k, h, z, \Gamma)$; and the transition function, $T$; such that $V$ and $F$ solve the households' problem under $T$. The competitive factor prices that satisfy the profit maximization conditions are consistent with the market clearing conditions $K=\int k_{i} d \Gamma$, and $H$ is equal to the measure of workers employed by the firms, ${ }^{3}$ and $T$ is consistent with $F$ and $\Pi$. By Walras' law, the goods market clears; that is, $C+K^{\prime}-(1-\delta) K=Y$, where $C=\int c_{i} d i$ is the aggregate consumption.

KS approximated the state variable $\Gamma$, which includes a capital distribution function by a finite vector of moments. They then show that the mean capital alone is sufficient for the approximation. We follow their approach and denote the approximated policy function for consumption by $c(k, h, z, K)$. We also approximate the transition function $T$ by a linear mapping of $\log K$. Following Maliar, Maliar and Valli (2010), we show that both the slope of the function and the constants can vary across $z$.

\section{Results}

\subsection{Government employment with balanced budget}

In this section, we numerically compute the equilibrium defined in the previous section. The government provides both the unemployment insurance and the additional employment

\footnotetext{
${ }^{3} H$ depends on the kind of policy. $H=\int h_{i} d \Gamma-\left(u_{0}-u_{z}\right)$ in the government employment policy and $H=\int h_{i} d \Gamma$ in the employment incentives policy.
} 
in state 1 , whereas it only provides the unemployment insurance in state 0 . The government employment program functions as a pure transfer, levying a lump-sum tax on the employed workers and distributing the proceeds to a fraction $u_{0}-u_{1}$ of the randomly selected unemployed workers. Since the government employment is non-productive, the aggregate production is not affected by this policy, unless the capital level changes.

The household policy functions and the exogenous state transition $\Pi$ constitute our generating process for household data. We generate a simulated path of an economy with $N=10,000$ households for 3,000 periods. The first 1,000 periods are discarded when computing the timeaverage of the aggregate variables. The standard errors of the time-average aggregates are computed from 50 simulated paths.

Table 1 shows the simulation results of the time-averaged aggregate consumption $C_{z}^{h}$ for different employment statuses, $h \in\{e, u\}$, and policy regimes, $z \in\{0,1\}$. $C_{z}$ is the time-averaged aggregate consumption during policy regime $z$. The column GE I in the table corresponds to the current benchmark model specification, where "GE" stands for government employment. We observe that when the policy regime is active $(z=1)$, the aggregate consumption level is higher $\left(C_{1}>C_{0}\right)$, the consumption level of the employed is lower $\left(C_{1}^{e}<C_{0}^{e}\right)$, and the consumption level of the unemployed is higher $\left(C_{1}^{u}>C_{0}^{u}\right)$. Table 2 shows the coefficient of variation in order to consider the within group consumption inequality. We find that both GE I and GE II can successfully reduce the household consumption inequality.

\begin{tabular}{c|ccc|ccc}
\hline \hline & \multicolumn{3}{|c}{ GE I } & \multicolumn{3}{c}{ GE II } \\
$z$ & $C_{z}^{e}$ & $C_{z}^{u}$ & $C_{z}$ & $C_{z}^{e}$ & $C_{z}^{u}$ & $C_{z}$ \\
\hline 0 & 2.5974 & 2.4682 & 2.5896 & 2.5699 & 2.3533 & 2.5569 \\
& $(0.0001)$ & $(0.0012)$ & $(0.0001)$ & $(0.0005)$ & $(0.0065)$ & $(0.0008)$ \\
1 & 2.5942 & 2.5188 & 2.5905 & 2.5722 & 2.4494 & 2.5662 \\
& $(0.0001)$ & $(0.0008)$ & $(0.0001)$ & $(0.0006)$ & $(0.0042)$ & $(0.0007)$ \\
$\log$ diff. & -0.0012 & 0.0199 & 0.0004 & 0.0009 & 0.0400 & 0.0037 \\
& $(0.0000)$ & $(0.0005)$ & $(0.0000)$ & $(0.0002)$ & $(0.0017)$ & $(0.0002)$ \\
\hline \hline
\end{tabular}

Table 1: Simulated average consumption for workers in different employment statuses, $(h \in$ $\{e, u\})$ and policy regimes, $(z \in\{0,1\})$. GE I is the case of transfers with a balanced budget, while GE II is the case of transfers with a constant tax.

\begin{tabular}{c|ccc|ccc}
\hline \hline & \multicolumn{3}{|c}{ GE I } & GE II \\
$z$ & $C V\left(C_{z}^{e}\right)$ & $C V\left(C_{z}^{u}\right)$ & $C V\left(C_{z}\right)$ & $C V\left(C_{z}^{e}\right)$ & $C V\left(C_{z}^{u}\right)$ & $C V\left(C_{z}\right)$ \\
\hline 0 & 0.1886 & 0.1828 & 0.1887 & 0.4974 & 0.4589 & 0.4963 \\
& $(0.0028)$ & $(0.0016)$ & $(0.0027)$ & $(0.0091)$ & $(0.0107)$ & $(0.0092)$ \\
1 & 0.1880 & 0.1794 & 0.1878 & 0.4949 & 0.4597 & 0.4938 \\
& $(0.0028)$ & $(0.0023)$ & $(0.0027)$ & $(0.0091)$ & $(0.0096)$ & $(0.0092)$ \\
$\log$ diff. & -0.0006 & -0.0034 & -0.0009 & -0.0025 & 0.0008 & -0.0025 \\
& $(0.0001)$ & $(0.0013)$ & $(0.0001)$ & $(0.0003)$ & $(0.0035)$ & $(0.0002)$ \\
\hline \hline
\end{tabular}

Table 2: Coefficient of variation of simulated consumption for workers in different employment statuses, $(h \in\{e, u\})$ and policy regimes, $(z \in\{0,1\})$.

Following the microeconometric literature, we call the selected unemployed as the treatment group and the other unselected who are not employed by the government as the control group. Using the simulated average consumption for each group, we can determine the positive 
treatment effect, which is calculated by the difference between the consumption change of the treatment group and that of the control group: $\log (2.5942 / 2.4682)-\log (2.5188 / 2.4682)=$ 0.0295 . Since the treatment group constitutes $1.25 \%$ of the labor force, the aggregated treatment effects amount to a $0.037 \%$ increase in aggregate consumption.

Figure 1 shows the policy function, $c(k, h, z, K)$, for the idiosyncratic states, $h \in\{u, e\}$, and the aggregate states, $z \in\{0,1\}$, while the aggregate capital is fixed at a simulated time-average level, $\bar{K}$. As can be seen from Figure 1 , household consumption nonlinearly depends on the household wealth level, $k$, especially in the domain of low-wealth. The observed concavity is interpreted as the precautionary saving motive of households, analytically shown by Carroll and Kimball (1996). In Appendix D.1, we confirm the interpretation of this concavity by a sensitivity analysis on risk aversion. In addition, we also find that the upward shift of the consumption function caused by active policy is most prominent for the low-wealth unemployed group. This indicates that an active policy decreases the precautionary savings of the unemployed: the government employment program shortens the expected unemployment duration, leading the unemployed to save less and consume more in the current period.

The decrease in the precautionary savings of the low-wealth unemployed leads to a decline in the aggregate capital level, $K$. The decline of $K$ increases the factor prices, and thus affects the household incomes. Hence, the simulated consumption responses consist of the effects of transfers across households and varied $K$ level. Because we are interested in the consumption response in a reduced-risk environment, we isolate the effect of the shift in $K$. To do so, we regress a simulated time series, $C_{z}$ on $K_{z}$ for each regime $z$ and interpolate $\hat{C}_{z}$ at the time-averaged aggregate capital level, $\bar{K}$. The column labeled " $K$ effect" in Table 3 shows the difference between $\log C_{1} / C_{0}$ and $\log \hat{C}_{1} / \hat{C}_{0}$. We find that the $K$ effect is almost zero. This is due to the fact that the movement of aggregate capital is quantitatively small in our GE I experiment. The $\log$ difference subtracted by the $K$ effect; that is, $\log \left(\hat{C}_{1} / \hat{C}_{0}\right)$, gauges the shift in aggregate consumption caused by a transfer policy where $K$ is kept constant at $\bar{K}$.

\begin{tabular}{c|ccccc}
\hline \hline & Log diff & $K$ effect & \multicolumn{3}{c}{ Risk effect } \\
& & & $\left(1-u_{0}\right) \log c_{1}^{e} / c_{0}^{e}$ & $u_{1} \log c_{1}^{u} / c_{0}^{u}$ & $\left(u_{0}-u_{1}\right) \log c_{1}^{e} / c_{0}^{u}$ \\
\hline GE I & 0.0004 & 0.0000 & -0.0005 & 0.0002 & 0.0005 \\
& $(0.0000)$ & $(0.0000)$ & $(0.0000)$ & $(0.0000)$ & $(0.0000)$ \\
GE II & 0.0037 & 0.0012 & 0.0009 & 0.0002 & 0.0006 \\
& $(0.0002)$ & $(0.0002)$ & $(0.0000)$ & $(0.0000)$ & $(0.0000)$ \\
\hline \hline
\end{tabular}

Table 3: Decomposition of aggregate consumption growth

To understand the remaining increase in aggregate consumption in the active regime of government employment, we analyze the consumption of three worker groups: the program participants, the employed nonparticipants, and the unemployed nonparticipants. We compute a consumption change by the transfer policy for each group based on the shift of policy functions in Figure 1. We do not use the simulated statistics reported in Table 1 because the simulated consumption is affected by shifts in $K$. We first evaluate the policy function at $(h, z, \bar{K})$ and $\left(h^{\prime}, z^{\prime}, \bar{K}\right)$ at the time-averaged aggregate capital $\bar{K}$, and then take a $\log$-difference $\log c_{z^{\prime}}^{h^{\prime}} / c_{z}^{h}$, where $c_{z}^{h}$ denotes $c\left(\bar{k}_{z}^{h}, h, z, \bar{K}\right)$ and $\bar{k}_{z}^{h}$ is the simulated average capital value in state $(h, z, \bar{K})$. The computed log-difference measure reflects the consumption response independent of the shift in $K$. The columns labeled under "Risk effect" in Table 3 show the consumption increase of each group in aggregate measured by the $\log$-difference, $\log c_{1}^{h^{\prime}} / c_{0}^{h}$, weighted by the fraction ${ }^{4}$

\footnotetext{
${ }^{4}$ The fractions of the groups are $1-u_{0}=94 \%$ for the employed nonparticipants, $u_{1}=4.83 \%$ for the unem-
} 
of each group.

First, we consider a change in the behavior of the program participants or the treatment group. We observe in the log-difference measure that their consumption level increases by $0.05 \%$ because their present and expected future incomes increase.

Second, we consider the employed nonparticipants whose employment status is unchanged under both regimes. The log-difference measure shows that their consumption level decreases by $0.05 \%$ with the regime switch. The behavior of this group of households is affected by the active policy in two ways. First, their tax burden increases. The cost of the passive policy is reduced, but this reduction is outweighed by the increase in the cost of the active policy. Second, their future expected labor income increases because the unemployment duration is reduced. The negative response of the simulated consumption implies that the negative tax effect outweighs the expected positive income effect.

Third, we consider the unemployed nonparticipants or the control group. Even though there are no direct concurrent benefits to them, the active policy increases the consumption of this group of households because the regime switch increases the expected job finding rate. This positive effect is confirmed by our simulation, which shows that their consumption level increases by $0.02 \%$.

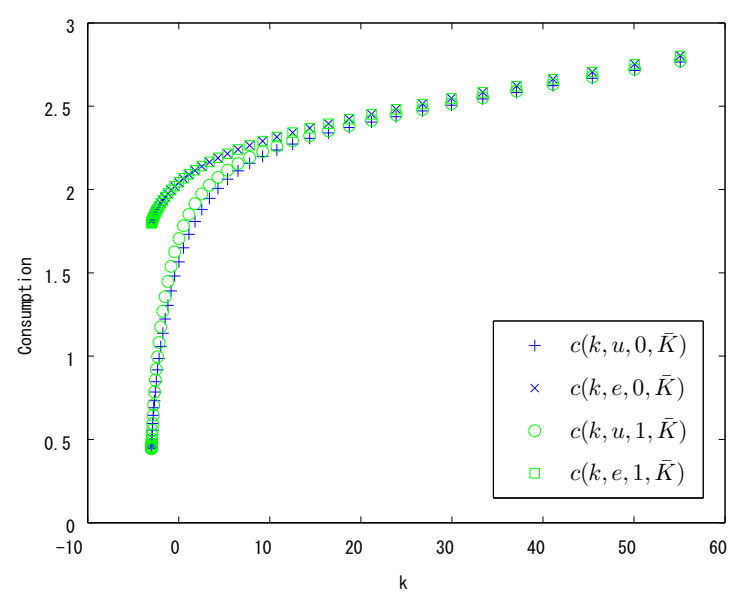

Figure 1: The approximated policy function for consumption. Given the average aggregate capital, $K$, the policy function of the unemployed in state $z_{t}=0$ is shown by the + line, that of the employed in state $z_{t}=0$ by the $\times$ line, that of the unemployed in state $z_{t}=1$ by the circle line, and that of the employed in state $z_{t}=1$ by the square line.

Our analysis of Table 3 confirms our previous analysis of the simulated data. Table 3 shows that the fall in consumption of the first group is roughly canceled out by the increase in consumption of the third group. This is natural because the active policy functions as a transfer of wealth from the first group to the third group. The net increase in total consumption is explained by the consumption increase of the second group, who is not involved in the transfer because it does not receive the transfer and is not taxed under the new policy. The second group consumes more because it now faces a reduced unemployment risk and begins to dissave its precautionary wealth. In total, "Log diff" summarizes the general equilibrium effect of the transfer policy. We observe a positive but limited impact on aggregate consumption. "Log diff" can be decomposed into a $K$ and Risk effect, and the latter effect can be decomposed into the

ployed nonparticipants, and $u_{0}-u_{1}=1.17 \%$ for the program participants, respectively. 
consumption responses of three groups. By this decomposition, we find that the unemployed nonparticipants play an important role in the increase in aggregate consumption.

\subsection{Government employment financed by a constant tax over time}

In the previous section, we could not directly observe how the employed nonparticipants benefit from a reduced unemployment risk, because the tax burden on the employed group increases during the period of active policy. This implies that we should observe the positive consumption response of the employed nonparticipants if the policy is financed by a tax that is constant over time across regimes.

This notion motivates our second model specification in which the transfer is financed by a constant tax and the government budget is allowed to have temporal imbalances. To isolate the response of the employed to a reduced unemployment risk from the increased tax burden, we devise an alternative model environment where the government has access to an international insurance market to finance a temporary transfer policy through constant taxation, which only requires the government budget to be balanced on average. In the international insurance market, our proposed government agrees to pay out the tax revenue it collects in every period, while it receives the necessary funds for the transfer policy when the policy randomly switches to an active regime. Specifically, the government swaps a stochastic transfer payment sequence, $\left\{\varepsilon_{t}\right\}$, for a fixed insurance cost sequence, $\{T\}$, such that $E\left(\varepsilon_{t}\right)=T$. The international insurance market is completely hedged by the law of large numbers that applies to the many participating governments.

The simulation results are reported under "GE II." Table 1 shows that both the employed and unemployed workers increase their consumption level when the policy switches to an active regime. "Log diff" in Table 3 shows that the policy switch results in a $0.37 \%$ increase in aggregate consumption. A decomposition of Table 3 shows that the employed workers significantly increase their consumption by $0.09 \%$, accounting for $52.9 \%$ of the consumption increase in response to a lower unemployment risk. Since a policy switch does not affect the tax paid by workers in each period and $K$ is set to be a constant, an increase in the expected lifetime income largely stems from the prospect of less unemployment risk. Therefore, a significant rise in the consumption level of the employed workers validates our argument that a reduced unemployment risk enhances the consumption demand of not only the unemployed but also the employed workers.

\subsection{An alternative policy experiment: corporate tax reduction}

In this section, we consider employment incentives as an alternative policy. In particular, we consider a regime-switching corporate tax rate, as in Davig (2004). By this policy, the government imposes a lower corporate tax on private firms to induce a larger labor demand. Therefore, the program participants are employed by private firms. Since the newly generated employment is productive, output varies endogenously as the policy regime switches.

We consider a case in which the government levies a flat-rate tax on the revenue of firms. The corporate tax rate, $\xi_{t}$, fluctuates between two states according to the Markov process specified by $\Pi$. In addition, we also assume an exogenous aggregate employment process that fluctuates between two states, $u_{0}$ and $u_{1}$, along with the policy status, $z \in\{0,1\}$. The mechanism underlying the employment incentives policy is that labor demand shifts out and employment increases when the tax rate is low. To implement such a mechanism in a simple model, we assume a particular kind of real wage rigidity: the after-tax real wage is held constant by an exogenously imposed norm in the labor market. As the tax rate changes, the employment level 
also changes so that the marginal product of labor is equal to the fixed after-tax real wage. We calibrate the tax rates such that the implied unemployment rates are equal to $u_{0}$ and $u_{1}$, as follows.

We set the constant after-tax real wage equal to the full-employment marginal product level $w=(1-\alpha) K^{\alpha}$. In each period, the production factors are paid for by their after-tax marginal products: $r=\left(1-\xi_{z}\right) \alpha\left(K /\left(1-u_{z}\right)\right)^{\alpha-1}$ and $w=\left(1-\xi_{z}\right)(1-\alpha)\left(K /\left(1-u_{z}\right)\right)^{\alpha}$. Then, we obtain the corporate tax rates that are consistent with our calibrated unemployment rates: $\xi_{z}=$ $1-\left(1-u_{z}\right)^{\alpha}, \quad z=0,1$. When $z_{t}=0$, the tax is high at $\xi_{0}$ and the unemployment level is high at $u_{0}$. When $z_{t}=1$, the tax is low at $\xi_{1}$ and the unemployment level is low at $u_{1}$. This specification can be used to interpret the numerical results, because we can eliminate the impacts of any aftertax wage fluctuations on the expected lifetime income, which directly reflects the changes in the magnitude of the unemployment risk.

Let us now consider two cases of employment incentives. In the first case, which we call "Tax I," the tax proceeds are rebated to the households in a lump-sum manner. By abuse of notation, we redefine $-\tau_{t}$ as the lump-sum transfer: $-\tau_{t}=\xi_{z} Y_{t}$. From this notation, the household's budget constraint can continue to be written as Equation (2). In the second case ("Tax II"), the tax proceeds are used by the government for non-productive activities. Here, the transfer, $\tau_{t}$, is zero for every $t$ and government expenditure, $G_{t}$, is equal to the tax proceeds, $\xi_{t} Y_{t}$. Government expenditure appears on the demand side of the goods-market clearing condition; that is, $C+K^{\prime}-(1-\delta) K+G=Y$. The Tax II specification serves a similar purpose as GE II. By holding the household income constant across regimes, this specification is useful for isolating the effects of a reduced unemployment risk.

\begin{tabular}{c|ccc|ccc}
\hline \hline & \multicolumn{3}{|c}{ Tax I } & \multicolumn{3}{c}{ Tax II } \\
$z$ & $C_{z}^{e}$ & $C_{z}^{u}$ & $C_{z}$ & $C_{z}^{e}$ & $C_{z}^{u}$ & $C_{z}$ \\
\hline 0 & 2.6010 & 2.4552 & 2.5923 & 2.5305 & 2.3876 & 2.5220 \\
& $(0.0008)$ & $(0.0023)$ & $(0.0008)$ & $(0.0048)$ & $(0.0013)$ & $(0.0015)$ \\
1 & 2.6021 & 2.5161 & 2.5980 & 2.5353 & 2.4512 & 2.5312 \\
& $(0.0009)$ & $(0.0017)$ & $(0.0009)$ & $(0.0014)$ & $(0.0034)$ & $(0.0015)$ \\
$\log$ diff. & 0.0004 & 0.0245 & 0.0022 & 0.0019 & 0.0263 & 0.0037 \\
& $(0.0002)$ & $(0.0008)$ & $(0.0002)$ & $(0.0003)$ & $(0.0010)$ & $(0.0037)$ \\
\hline \hline
\end{tabular}

Table 4: Consumption changes in policy transitions for the average workers in different groups. Tax I is the case of a corporate tax with lump-sum rebates and Tax II is the case of a corporate tax and wasteful government spending.

\begin{tabular}{c|ccc|ccc}
\hline \hline & \multicolumn{3}{|c}{ Tax I } & \multicolumn{4}{c}{ Tax II } \\
$z$ & $C V\left(C_{z}^{e}\right)$ & $C V\left(C_{z}^{u}\right)$ & $C V\left(C_{z}\right)$ & $C V\left(C_{z}^{e}\right)$ & $C V\left(C_{z}^{u}\right)$ & $C V\left(C_{z}\right)$ \\
\hline 0 & 0.2857 & 0.2576 & 0.2848 & 0.2785 & 0.2523 & 0.2776 \\
& $(0.0042)$ & $(0.0029)$ & $(0.0041)$ & $(0.0150)$ & $(0.0126)$ & $(0.0149)$ \\
1 & 0.2847 & 0.2604 & 0.2839 & 0.2772 & 0.2543 & 0.2765 \\
$\log$ diff. & $(0.0042)$ & $(0.0031)$ & $(0.0041)$ & $(0.0150)$ & $(0.0133)$ & $(0.0149)$ \\
& -0.0010 & 0.0027 & -0.0008 & -0.0012 & 0.0020 & -0.0011 \\
& $(0.0001)$ & $(0.0018)$ & $(0.0001)$ & $(0.0002)$ & $(0.0021)$ & $(0.0001)$ \\
\hline \hline
\end{tabular}

Table 5: Coefficient of variation of simulated consumption for workers in different groups. 


\begin{tabular}{c|ccccc}
\hline \hline & Log diff & $K$ effect & $\left(1-u_{0}\right) \log c_{1}^{e} / c_{0}^{e}$ & $u_{1} \log c_{1}^{u} / c_{0}^{u}$ & $\left(u_{0}-u_{1}\right) \log c_{1}^{e} / c_{0}^{u}$ \\
\hline Tax I & 0.0022 & 0.0012 & 0.0001 & 0.0002 & 0.0005 \\
& $(0.0002)$ & $(0.0002)$ & $(0.0000)$ & $(0.0000)$ & $(0.0000)$ \\
Tax II & 0.0037 & 0.0018 & 0.0009 & 0.0002 & 0.0005 \\
& $(0.0002)$ & $(0.0003)$ & $(0.0000)$ & $(0.0000)$ & $(0.0000)$ \\
\hline \hline
\end{tabular}

Table 6: Decomposition of aggregate consumption growth

Table 4 shows the consumption for various states. Note that consumption increases in the periods of low tax for all workers in Tax I as well as Tax II. Table 5 shows the coefficient of variation in order to consider the within group consumption inequality. As with GEs, we find that both Tax I and Tax II can reduce the consumption inequality. Table 6 shows the decomposition of the total consumption growth in terms of the contribution of the worker groups according to their employment status. The first group accounts for $13 \%$ and the third group accounts for $63 \%$ of the consumption variation in response to less unemployment risk.

In Tax I, the tax proceeds are rebated back to the households and therefore the tax functions as a distortionary transfer. The lower tax rate induces a higher labor demand and larger output. Given the real wage rigidity, the lump sum transfer to the households is reduced during the low-tax active policy periods. The reduced transfer income negatively affects the consumption demand of the unemployed. Nonetheless, the unemployed group positively contributes to the increase in consumption by $0.02 \%$ through the tax reduction, as shown in Table 6 . This implies that the wealth effect of a lower unemployment risk overwhelms the effect of a reduced transfer income.

The wealth effect can be more directly observed in Tax II. Here, both the real wage and government transfers (zero) are fixed during the policy transitions. Hence, the contemporaneous income of the employed workers is not affected by the policy at all. Therefore, the consumption increase is due to a policy switch for the employed $(0.09 \%)$ indicates a pure effect of the reduced unemployment risk. This effect is larger than that in Tax I $(0.01 \%)$. While a tax cut is always accompanied by a reduced rebate in Tax I, there is no rebate in Tax II. Therefore, we expect a larger impact of a policy switch in Tax II, and the numerical result confirms our belief.

\section{Conclusion}

In this paper, we consider two kinds of labor demand policies and find the general equilibrium effects of these policies on aggregate consumption demand. The direct job creation by the government employment model provides a simple case that facilitates the interpretation of the basic mechanisms and numerical results, whereas the model with employment incentives because of a corporate tax reduction examines how a policy directly affects production activities in the private sector. By these four experiments, we find that active labor market policies can lead to a quantitatively large increase in the aggregate consumption demand, which can further lead to an increase in the aggregate consumption level if the supply of goods elastically conforms to the increase in consumption demand. 


\section{References}

Aiyagari, S. Rao (1994) 'Uninsured idiosyncratic risk and aggregate saving.' Quarterly Journal of Economics 109, 659-84

Calmfors, L. (1994) 'Active labour market policy and unemployment - a framework for the analysis of crucial design features.' OECD Economic studies 22, 7-47

Carroll, Christopher D. (2001) 'A theory of the consumption function, with and without liquidity constraints.' Journal of Economic Perspectives 15, 23-45

Carroll, Christopher D., and Miles S. Kimball (1996) 'On the concavity of the consumption function.' Econometrica 64, 981-992

Cogan, John F., and John B. Taylor (2012) 'What the government purchases multiplier actually multiplied in the 2009 stimulus package.' In 'Government Policies and the Delayed Economic Recovery' (Hoover Institution, Stanford University)

Davidson, Carl, and Stephen A Woodbury (1993) 'The displacement effect of reemployment bonus programs.' Journal of Labor Economics 11(4), 575-605

Davig, Troy (2004) 'Regime-switching debt and taxation.' Journal of Monetary Economics $51,837-859$

Engen, Eric M., and Jonathan Gruber (2001) 'Unemployment insurance and precautionary saving.' Journal of Monetary Economics 47, 545-579

Heathcote, Jonathan (2005) 'Fiscal policy with heterogeneous agents and incomplete markets.' Review of Economic Studies 72, 161-188

Heckman, James, Lance Lochner, and Christopher Taber (1998) 'Explaining Rising Wage Inequality: Explanations With A Dynamic General Equilibrium Model of Labor Earnings With Heterogeneous Agents.' Review of Economic Dynamics 1(1), 1-58

Heckman, James, Robert Lalonde, and Jeffrey Smith (1999) 'The economics and econometrics of active labor market programs.' In 'Handbook of Labor Economics,' vol. 3 of Handbook of Labor Economics chapter 31, pp. 1865-2097

Huggett, Mark (1997) 'The one-sector growth model with idiosyncratic shocks: Steady states and dynamics.' Journal of Monetary Economics 39, 385-403

Krusell, Per, and Anthony A. Smith, Jr. (1998) 'Income and wealth heterogeneity in the macroeconomy.' Journal of Political Economy 106, 867-896

Lusardi, Annamaria (1997) 'Precautionary saving and subjective earnings variance.' Economics Letters 57, 319-326

Maliar, Lilia, Serguei Maliar, and Fernando Valli (2010) 'Solving the incomplete markets model with aggregate uncertainty using the Krusell-Smith algorithm.' Journal of Economic Dynamics and Control 34, 42-49

Meyer, Bruce (1995) 'Lessons from the U.S. unemployment insurance experiments.' Journal of the Economic Literature 33(1), 91-131 
Nie, Jun, and Ethan Struby (2011) 'Would active labor market policies help combat high U.S. unemployment?' Economic Review (Q III), 35-69

Oh, Hyunseung, and Ricardo Reis (2012) 'Targeted transfers and the fiscal response to the great recession.' Journal of Monetary Economics 59, 50-64 